\title{
Is type 2 diabetes an amyloidosis and does it really matter (to patients)?
}

\author{
G. J. S. Cooper · J. F. Aitken $\cdot$ S. Zhang
}

Received: 8 February 2010 / Accepted: 10 February 2010 /Published online: 13 March 2010

(C) Springer-Verlag 2010

\begin{abstract}
Abbreviations
AFM Atomic force microscopy

hIAPP Human islet amyloid polypeptide
\end{abstract}

Degeneration of pancreatic islet beta cells is increasingly ranked as a key disease mechanism in type 2 diabetes [1, 2], but it is not entirely clear what the underlying molecular processes might be and how they attack insulin production, ultimately causing type 2 diabetes [3, 4].

However, recent studies based on quantitative measurements in post mortem pancreatic tissue from humans with type 2 diabetes have reinforced earlier observations concerning the probable role of lowered beta cell numbers $[5,6]$ and pointed to a linkage between beta cell disappearance and beta cell apoptosis [7, 8].

'Glucotoxicity' and 'lipotoxicity' are widely discussed possible causes of beta cell failure, but both are thought to exert their effects only after significant metabolic deterio-

G. J. S. Cooper $(\bowtie) \cdot$ J. F. Aitken $\cdot$ S. Zhang

School of Biological Sciences, and Maurice Wilkins

Centre of Excellence for Molecular Biodiscovery,

Faculty of Science, University of Auckland,

Auckland, New Zealand

e-mail: g.cooper@auckland.ac.nz

\section{G. J. S. Cooper}

Department of Pharmacology, Medical Sciences Division, University of Oxford,

Oxford, UK ration and functional islet impairment are already well underway [9] and so cannot be the prime movers.

So what might the initiating insults be? Recent data from genome-wide association studies have highlighted the impact of particular alleles of certain susceptibility genes, giving further support to the idea that beta cell abnormalities are fundamental in the pathogenesis of this disease [4]. Some of these alleles encode variants of certain beta cell proteins linked to insulin production and/or secretion, and can hasten the development of functional islet deterioration and diabetes onset in carriers [1, 2]. However, currently identified alleles do not provide an explanation for most cases of 'common or garden' type 2 diabetes [10].

Against this background, Zraika et al. in this issue of Diabetologia have reviewed aspects of another, underappreciated phenomenon, which could well initiate beta cell degeneration in type 2 diabetes [11]. As they point out, it has long been known that many [8, 12-14] or perhaps most $[15,16]$ type 2 diabetic patients are found to have islet amyloid deposits adjacent to their beta cells [17] when post mortem pancreatic tissue is examined histologically. Although islet amyloid has also been reported to occur in numbers of humans not known to have diabetes, the author of a major study cautioned that 'nondiabetic persons with hyaline islets may represent individuals with undiagnosed or potential diabetes' [18]. Varying sensitivities of different histological methods may also have contributed to betweenstudy differences in prevalence estimates [11].

Islet amyloid, or hyaline as it was once known [12], has the beta cell hormone human amylin or human islet 
amyloid polypeptide (hIAPP) $[17,19,20]$ as its monomer and arguably prompted the finding that first pin-pointed the islets as the likely location of diabetes causation [12]. Paradoxically, in marked contrast with amyloid-associated neurodegenerative diseases in neuropathology, this observation has so far received little recognition in the wider diabetes research field.

The presence of islet amyloid in most patients supports the classification of type 2 diabetes as an amyloidosis, alongside prominent neurodegenerative disorders including Alzheimer's [21], Parkinson's [22] and Huntington's diseases [23], and prion-mediated conditions like CreutzfeldtJakob disease and bovine spongiform encephalopathy [24, 25].

Misfolding of syndrome-specific proteins, termed 'monomers', leading to the formation of tissue-resident aggregates, or amyloid, formed mainly from polymorphic assemblies of these monomers [26], is clearly implicated in the pathogenesis of the neurodegenerative diseases mentioned above. There is also a group of genetically transmitted forms of amyloidosis, in which coding mutations in specific monomers cause pathogenic gainsof-function (amyloid formation and toxicity) [27-30]. For each of these diseases, many lines of evidence now link processes associated with misfolding of the diseasespecific monomers to the co-localised tissue damage that causes each syndrome.

So can type 2 diabetes, where amyloid formation clearly occurs in close proximity to the neuron-like [31] beta cells, really be a standout exception from all other forms of amyloidosis? We think not. Furthermore, human amylin kills neuronal cells in culture through an apoptotic process similar to that by which it kills beta cells, pointing to significant linkages between its effects in these two lineages [32].

Although supported by some, the notion that type 2 diabetes is indeed a form of amyloidosis is not widely agreed upon by specialist diabetes researchers. Several questions need to be comprehensively answered before the notion is accepted. For example, is islet amyloid 'chicken' or 'egg' in islet degeneration, i.e. could the amyloid be secondary to the diabetic state, rather than causative? Why, if amyloidosis causes beta cell degeneration, is there not a closer physical association between amyloid deposits and areas of beta cell deficit? What exactly is meant by the term 'amyloid' in the diabetes context? How might islet amyloidosis cause diabetes? And finally, why would this information be of any use, if the amyloid-associated processes cannot be targeted to generate new and improved glucose-lowering therapies?

It is towards the answers to these and related questions that the main thrust of Zraika et al.'s review is addressed. In recent years, as the authors point out, two main hypotheses have emerged that provide a possible framework in which to address such questions. Both, in fact, stem from the same underlying idea, which is that something produced by the aggregation of monomers kills beta cells. Similar phenomena probably occur in all amyloid syndromes.

So what could that something be? This is the focus of the fundamental question addressed by Zraika et al. All amyloid monomers undergo aggregation in vitro and, perhaps more informatively, form amyloids in vivo. There are many examples where acquisition of the propensity to aggregate, through a change in amino acid sequence, confers cytotoxic and amyloidogenic properties upon a previously non-amyloidogenic protein: this can happen through spontaneous genetic mutation [28-30] or via evolutionary processes, the latter being the case for human amylin [19, 33, 34]. In vitro structure-activity relationships show that monomers contain an amyloidogenic sequence $[33,34]$, in which amyloid formation and cytoxicity are apparently driven by a relatively circumscribed number of amino acid residues.

These matters are all generally agreed and not particularly controversial, but hereabouts many uncertainties begin to emerge, as highlighted in the review. Human amylin's physiological conformation is one of random coil, but it undergoes rapid conformational change into $\beta$-conformers when placed in physiological solutions [35]. Based on the available evidence, many workers have concluded that small oligomers formed by aggregated human amylin [36, 37] are probably the species that could ultimately cause diabetes [38, 39]. Others, among them Zraika and colleagues, believe that the cytotoxicity of larger amyloid fibrils must be considered [11, 15], as indeed it must. One pertinent question that then arises is whether this difference really matters. We shall return to this point below.

In type 2 diabetes, there is in vitro evidence that intermediates formed during the aggregation process itself may actually initiate cell death via apoptosis [40-42]. Oligomers are now known to form spontaneously in human amylin solutions, among and often concomitantly with the larger, precipitable fibrillar structures that have typically been visualised by electron microscopy [26]. Amylin oligomers, which are usually at least two orders of magnitude smaller than fibrils, are initially a few $\mathrm{nm}$ in diameter [37]. Application of real-time atomic force microscopy (AFM) has enabled measurement of their dimensions, mass and time-dependent growth [36, 37]. When amylin monomers first become visible in the AFM, they comprise structured assemblies of some 16 monomers, which grow over minutes by rapid bidirectional elongation through the addition of further monomers at a roughly constant rate [37]. Time-dependent growth is an intrinsic property of oligomers that might be related to their toxicity [40] and may well provide an explanation for the differing 
estimates of oligomer mass highlighted by Zraika et al. In reality, AFM data indicate that there is no single oligomer, but rather a rapidly shifting population of related oligomeric nanoparticles, which shift seamlessly between each other over time. This is the reality that now needs to be confronted by the research field.

As Zraika et al. point out, to date all direct observations concerning oligomers have been made in vitro, with no direct in vivo evidence for formation of cytotoxic oligomers in the islets or their contribution to cytotoxicity. Thus, to glean further information on the putative role(s) of oligomers in cytotoxicity and islet degeneration, investigators have to rely on a balance of the available indirect evidence. It is equally important, however, to remember that absence of evidence is not evidence of absence, i.e. just because the fibrils are more easily visualised by existing histological methods does not prove that cytotoxic oligomers are any less likely to be present in tissues.

Another question asked by Zraika et al. is to what degree oligomers, as opposed to larger fibrils, might contribute to cytotoxicity and the development of diabetes [43]. Many in vitro experiments have employed conditions where fibrils and oligomers form together, and so cannot be used to differentiate between these two possibilities. Some studies, particularly those of Konarkowska et al. [40], have compared the cytotoxicity of preparations in which human amylin was present as pre-formed fibrils (high $\beta$-sheet content invariant over time as determined by circular dichroism spectroscopy) with those in which it was initially present mainly in random coiled structures and underwent time-dependent $\beta$-sheet formation. Only the latter preparations were cytotoxic, pointing to intermediates in the aggregation pathway as potential triggers of cytotoxicity, at least in vitro. Furthermore, experiments with truncated human amylin homologues established that the cytotoxic signal was transmitted via receptors that were not typical systemic amylin receptors [40]. Such experiments do not, however, differentiate between the two hypotheses of Zraika et al., since both species are present simultaneously. Notably, however, Lin et al. have provided indirect evidence of the occurrence of oligomers in islet tissue and linked them to cytotoxicity through their application of conformation-dependent anti-oligomer-specific antibodies [44]. Caution is nevertheless still warranted in the interpretation of exactly what those studies tell us [11].

Zraika et al. have argued that mature amyloid fibrils, rather than small, soluble cytotoxic oligomers [37-39, 43], could play the main role in beta cell degeneration and diabetes causation. As noted, they have pointed to the numerous weaknesses and shortcomings of the currently available evidence, and in so doing have indicated further lines of investigation that might improve our understanding. However, the question remains of whether the evidence supporting the converse idea, namely that mature fibrils are cytotoxic, really stacks up? The authors concede that, just as for oligomers, this evidence is mainly indirect and therefore subject to the same caveats as those applying to oligomers.

What do we know of the molecular processes that might link amylin misfolding to diabetes, and can they be beneficially targeted to suppress diabetes? There is emerging evidence, discussed below, that targeting amylin misfolding to suppress diabetes might well be an attainable goal in the not-too-distant future [39].

For the past two decades, information concerning amylin misfolding has been derived mainly from in vitro studies of amylin solutions and in vivo observations in patient-derived tissues or lines of human amylin/hIAPP transgenic mice. Many sophisticated, specialised physical methods have been applied to analyse the solution and solid-state behaviours of various amylin homologues; and with the exception of two studies, which measured systemic responses to ex vivo isolates of human pancreatic amylin [45, 46], these studies have all used synthetic preparations (see review by Cooper [47]). In our experience, the methods that measure the properties of individual aggregates, rather than of bulk assemblages have generally been more informative. For example, scanning-transmission electron microscopy has enabled detection and measurement of the amylin protofibril, the probable basecomponent of the higher order structures in amyloid deposits [26], and AFM has charted the dimensions and kinetics of amylin oligomer formation [37]. Zraika et al. point out that many of the biophysical methods that have been informative for evaluating the properties of amyloidogenic monomers such as A $\beta$ (the monomer of Alzheimer's disease) have proven much less effective where human amylin is concerned, probably because of its high propensity to aggregate more rapidly in aqueous solutions. Thus, classical techniques such as light scattering and analytical ultracentrifugation have been relatively uninformative when applied to human amylin. These limitations may have contributed to the slower uptake of amylin-related mechanisms into mainstream diabetes research.

Many open questions remain concerning the molecular and cellular linkages between amylin aggregation and diabetes. Islet amyloid tends to occur mainly in the extracellular space and amylin is a physiological component of the insulin granule that is secreted on to the cell surface, so it is logical to investigate how extracellular amylin might cause cell death [48]. In brief, there is much evidence that aggregating amylin evokes cytotoxicity through an apoptotic mechanism [48] mediated via a pathway comprising initial activation of a cell membranebound Fas/Fas ligand/Fas-associated death domaincontaining protein/caspase- 8 complex [41, 42, 49], followed 
by a three-pronged downstream cascade comprising cJun amino-terminal kinase 1/cJun [41], activating transcription factor 2/p38 mitogen-activated protein kinase [50] and p53/ p21 wild-type p53-activated fragment 1/p21 cyclindependent kinase-interacting protein 1 pathways [48], which results ultimately in activation of caspase-3 [41] and cell death. Haataja et al., in a review [38], have reported on their parallel studies of an amylin-mediated pathway, whereby activation of a mechanism related to endoplasmic reticulum stress might also contribute to islet beta cell degeneration.

So does the central question that Zraika et al. have set out to address really matter? We think it does.

The pathobiology of human amylin and its links to diabetes have been investigated in numerous lines of human amylin transgenic mice. Many such lines, for example those in which the transgene was inserted into a C57BL background, do not develop spontaneous diabetes [5153]. However, other lines, whose genetic background is $\mathrm{FVB} / \mathrm{N}$, develop spontaneous diabetes and islet amyloid $[39,54,55]$, presenting an opportunity to probe the relationship between these two phenomena and to measure the impact of experimental therapies on both.

We have now developed lines of human amylin transgenic mice in which hemizygous animals develop spontaneous diabetes with high penetrance ( 95\%) [39]. Diabetes in these mice is caused by initial islet beta cell dysfunction followed later by progressive beta cell loss and progressively worsening hyperglycaemia. Islet amyloid is absent from all homozygous transgenic animals, which express a severe diabetes phenotype, and also from hemizygous animals with early-onset diabetes. In animals with islet amyloid, amyloid area correlates positively, not negatively, with longevity. Some long-lived non-diabetic hemizygous animals also have large islet amyloid areas, showing that amyloid itself is not intrinsically cytotoxic. Oral tetracycline, a modifier of human amylin misfolding [56], dose-dependently ameliorates hyperglycaemia and polydipsia, delays rates of diabetes initiation and progression, and markedly increases longevity compared with water-treated controls. Thus, treatment with tetracycline ameliorates diabetes in these animals.

We find these data difficult to reconcile with the notion that cytotoxicity of fibrillar islet amyloid contributes significantly to pathogenesis of diabetes. Rather, we interpret them to indicate that microscopically evident fibrillar amyloid is neither necessary nor sufficient to cause diabetes, but rather that it is positively correlated with longevity; in short, that it is protective. These findings are consistent with results from related fields, where researchers have shown that other amyloids are also likely to have a protective function [57]. Interventions with compounds such as tetracycline that inhibit misfolding [56] and are capable of suppressing diabetes, but which leave (protective) islet amyloid formation intact, may have potential for treating or preventing type 2 diabetes, although further discussion will be required before trials of such agents can be initiated.

In summary, irrespective of the relative pathogenetic roles of amylin oligomers or mature fibrils, these data, taken together, provide a compelling argument that type 2 diabetes should indeed be classified as a form of amyloidosis; and yes, it really does matter!

Duality of interest The authors declare that there is no duality of interest associated with this manuscript.

\section{References}

1. Hamming KSC, Soliman D, Matemisz LC et al (2009) Coexpression of the type 2 diabetes susceptibility gene variants KCNJ11 E23K and ABCC8 S1369A alter the ATP and sulfonylurea sensitivities of the ATP-sensitive $\mathrm{K}^{+}$channel. Diabetes 58:2419-2424

2. Jonsson A, Isomaa $B$, Tuomi $T$ et al (2009) A variant in the KCNQ1 gene predicts future type 2 diabetes and mediates impaired insulin secretion. Diabetes 58:2409-2413

3. Leahy JL (1990) Natural history of $\beta$-cell dysfunction in NIDDM. Diabetes Care 13:992-1010

4. Leahy JL (2005) $\beta$-cell dysfunction in type 2 diabetes mellitus. In: Kahn CR, Weir GC, King GL, Jacobson AM, Moses AC, Smith RJ (eds) Joslin's diabetes mellitus, 14th edn. Lippincott, Williams and Wilkins, Philadelphia, pp 449-461

5. Gepts W (1981) Islet changes in human diabetes. In: Cooperstein GJ, Watkins D (eds) The islets of Langerhans. Academic, New York, pp 321-356

6. Clark A, Wells CA, Buley ID et al (1988) Islet amyloid, increased A-cells, reduced B-cells and exocrine fibrosis: quantitative changes in the pancreas of type 2 diabetic patients. Diabetes Res 9:151-159

7. Butler AE, Janson J, Bonner-Weir S, Ritzel R, Rizza RA, Butler PC (2003) $\beta$-cell deficit and increased $\beta$-cell apoptosis in humans with type 2 diabetes. Diabetes 52:102-110

8. Deng S, Vatamaniuk M, Huang X et al (2004) Structural and functional abnormalities in the islets isolated from type 2 diabetic subjects. Diabetes 53:624-632

9. Poitout V, Robertson RP (2002) Secondary beta-cell failure in type 2 diabetes - a convergence of glucotoxicity and lipotoxicity. Endocrinol 143:339-342

10. Frayling TM (2007) Genome-wide association studies provide new insights into type 2 diabetes aetiology. Nat Rev Genet 8:657662

11. Zraika S, Hull RL, Verchere CB et al (2010) Toxic oligomers and islet beta-cell death: guilty by association or convicted by circumstantial evidence? Diabetologia. doi:10.1007/s00125-0101671-6

12. Opie EL (1900-01) The relation of diabetes mellitus to lesions of the pancreas. Hyaline degeneration of the islands of Langerhans. J Exp Med 5:527-540

13. Bell ET (1952) Hyalinization of the islet of Langerhans in diabetes mellitus. Diabetes 1:341-344 
14. Zhao HL, Lai FM, Tong PC et al (2003) Prevalence and clinicopathological characteristics of islet amyloid in Chinese patients with type 2 diabetes. Diabetes 52:2759-2766

15. Clark A, Cooper GJS, Lewis CE et al (1987) Islet amyloid formed from diabetes-associated peptide may be pathogenic in type-2 diabetes. Lancet ii:231-234

16. Westermark P (1972) Quantitative studies on amyloid in the islets of Langerhans. Ups J Med Sci 77:91-94

17. Cooper GJS, Willis AC, Clark A, Turner RC, Sim RB, Reid KBM (1987) Purification and characterization of a peptide from amyloid-rich pancreases of type 2 diabetic patients. Proc Natl Acad Sci U S A 84:8628-8632

18. Bell ET (1959) Hyalanization of the islets of Langerhans in nondiabetic individuals. Am J Pathol 35:801-805

19. Cooper GJS (1994) Amylin compared with calcitonin gene-related peptide: structure, biology, and relevance to metabolic disease. Endocr Rev 15:163-201

20. Westermark P, Wernstedt C, Wilander E, Hayden DW, O'Brien TD, Johnson KH (1987) Amyloid fibrils in human insulinoma and islets of Langerhans of the diabetic cat are derived from a neuropeptide-like protein also present in normal islet cells. Proc Natl Acad Sci U S A 84:3881-3885

21. Hardy J, Selkoe DJ (2002) The amyloid hypothesis of Alzheimer's disease: progress and problems on the road to therapeutics. Science 297:353-356

22. Goldberg MS, Lansbury PT Jr (2000) Is there a cause-and-effect relationship between alpha-synuclein fibrillization and Parkinson's disease? Nat Cell Biol 2:E115-E119

23. Hatters DM (2008) Protein misfolding inside cells: the case of huntingtin and Huntington's disease. IUBMB Life 60:724-728

24. Thompson AJ, Barrow CJ (2002) Protein conformational misfolding and amyloid formation: characteristics of a new class of disorders that include Alzheimer's and Prion diseases. Curr Med Chem 9:1751-1762

25. Smirnovas V, Kim JI, Lu X, Atarashi R, Caughey B, Surewicz WK (2009) Distinct structures of scrapie prion protein $\left(\operatorname{PrP}_{\mathrm{SC}}\right)$ seeded vs spontaneous recombinant prion protein fibrils revealed by hydrogen/deuterium exchange. J Biol Chem 284:2423324241

26. Goldsbury CS, Cooper GJS, Goldie KN et al (1997) Polymorphic fibrillar assembly of human amylin. J Struct Biol 119:17-27

27. Cardoso I, Saraiva MJ (2005) Doxycycline disrupts transthyretin amyloid: evidence from studies in a FAP transgenic mice model. FASEB J 20:234-239

28. Benson MD, Wallace MR (1989) Amyloidosis. In: Scriver CR, Beaudet AL, Sly WS, Valle D (eds) The metabolic basis of inherited disease: volume II. McGraw Hill, New York, pp 24392460

29. Sousa MM, Cardoso I, Fernandes R, Guimaraes A, Saraiva MJ (2001) Deposition of transthyretin in early stages of familial amyloidotic polyneuropathy: evidence for toxicity of nonfibrillar aggregates. Am J Pathol 159:1993-2000

30. Palsdottir A, Helgason A, Palsson S et al (2008) A drastic reduction in the life span of cystatin C L68Q carriers due to lifestyle changes during the last two centuries. PLoS Genet 4: e1000099

31. Atouf F, Czernichow P, Scharfmann R (1997) Expression of neuronal traits in pancreatic $\beta$-cells: implication of neuronrestrictive silencing factor/repressor element silencing transcription factor, a neuron-restrictive silencer. J Biol Chem 272: 1929-1934

32. MacGibbon G, Cooper GJS, Dragunow M (1998) Acute application of amylin, unlike $\beta$-amyloid peptides, kills undifferentiated PC12 cells by apoptosis. Neuroreport 8:3945-3949

33. Westermark P, Engström U, Johnson KH, Westermark GT, Betsholtz C (1990) Islet amyloid polypeptide: pinpointing amino acid residues linked to amyloid fibril formation. Proc Natl Acad Sci U S A 87:5036-5040

34. Cooper GJS, Day AJ, Willis AC, Roberts AN, Reid KBM, Leighton B (1989) Amylin and the amylin gene: structure, function, and relationship to islet amyloid and to diabetes mellitus. Biochim Biophys Acta 1014:247-258

35. Goldsbury C, Goldie K, Pellaud J et al (2000) Amyloid fibril formation from full-length and fragments of amylin. J Struct Biol 130:352-362

36. Goldsbury C, Kistler J, Aebi U, Arvinte T, Cooper GJS (1999) Watching amyloid fibrils grow by time lapse atomic force microscopy. J Mol Biol 285:33-39

37. Green JD, Goldsbury C, Kistler J, Cooper GJS, Aebi U (2004) Human amylin oligomer growth and fibril elongation define two distinct phases in amyloid formation. J Biol Chem 279:1220612212

38. Haataja L, Gurlo T, Huang CJ, Butler PC (2008) Islet amyloid in type 2 diabetes, and the toxic oligomer hypothesis. Endocr Rev 29:303-316

39. Aitken JF, Loomes KM, Scott DW et al (2010) Tetracycline treatment retards the onset and slows the progression of diabetes in human amylin transgenic mice. Diabetes 59:161-171

40. Konarkowska B, Aitken JF, Kistler J, Zhang S, Cooper GJS (2006) The aggregation potential of human amylin determines its cytotoxicity towards islet beta-cells. FEBS J 273:3614-3624

41. Zhang S, Liu J, Dragunow M, Cooper GJS (2003) Fibrillogenic amylin evokes islet $\beta$-cell apoptosis through linked activation of a caspase cascade and JNK1. J Biol Chem 278:52810-52819

42. Zhang S, Liu H, Yu H, Cooper GJS (2008) Fas-associated death receptor signaling evoked by human amylin in islet $\beta$-cells. Diabetes 57:348-356

43. Janson J, Ashley RH, Harrison D, McIntyre S, Butler PC (1999) The mechanism of islet amyloid polypeptide toxicity is membrane disruption by intermediate-sized toxic amyloid particles. Diabetes 48:491-498

44. Lin CY, Gurlo T, Kayed R et al (2007) Toxic human islet amyloid polypeptide (h-IAPP) oligomers are intracellular, and vaccination to induce anti-toxic oligomer antibodies does not prevent h-IAPPinduced beta-cell apoptosis in h-IAPP transgenic mice. Diabetes 56:1324-1332

45. Leighton B, Cooper GJS (1988) Pancreatic amylin and calcitonin gene-related peptide cause resistance to insulin in skeletal muscle in vitro. Nature 335:632-663

46. Roberts AN, Leighton B, Todd JA et al (1989) Molecular and functional characterization of amylin, a peptide associated with type 2 diabetes mellitus. Proc Natl Acad Sci U S A 86:9662-9666

47. Cooper GJS (2001) Amylin: physiology and pathophysiology. In: Jefferson LS, Cherrington AD (eds) The handbook of physiology, section 7, the endocrine pancreas and regulation of metabolism. American Physiological Society, Oxford University Press, New York, pp 303-396

48. Zhang S, Liu J, Saafi EL, Cooper GJS (1999) Induction of apoptosis by human amylin in RINm5F islet $\beta$-cells is associated with enhanced expression of $\mathrm{p} 53$ and $\mathrm{p} 21 \mathrm{WAF} 1 / \mathrm{CIP} 1$. FEBS Lett 455:315-320

49. Saafi E, Konarkowska B, Zhang S, Kistler J, Cooper GJS (2001) Ultrastructural evidence that apoptosis is the mechanism by which human amylin evokes death in RINm5F pancreatic islet $\beta$-cells. Cell Biol Int 25:339-350

50. Zhang S, Liu H, Liu J, Tse CA, Dragunow M, Cooper GJS (2006) Activation of activating transcription factor 2 by p38 MAP kinase during apoptosis induced by human amylin in cultured pancreatic $\beta$-cells. FEBS J 273:3779-3791

51. Fox N, Schrementi J, Nishi M et al (1993) Human islet amyloid polypeptide transgenic mice as a model of non-insulin-dependent diabetes mellitus (NIDDM). FEBS Lett 323:40-44 
52. Verchere CB, D'Alessio DA, Palmiter RD, Kahn SE (1994) Transgenic mice overproducing islet amyloid polypeptide have increased insulin storage and secretion in vitro. Diabetologia 37:725-728

53. de Koning EJP, Morris ER, Hofhuis FM et al (1994) Intraand extracellular amyloid fibrils are formed in cultured pancreatic islets of transgenic mice expressing human islet amyloid polypeptide. Proc Natl Acad Sci U S A 91:84678471

54. Janson J, Soeller WC, Roche PC et al (1996) Spontaneous diabetes mellitus in transgenic mice expressing human islet amyloid polypeptide. Proc Natl Acad Sci U S A 93:72837288

55. Wong WPS, Scott DW, Ferreira A et al (2008) Spontaneous diabetes in hemizygous human amylin transgenic mice that developed neither islet amyloid nor peripheral insulin resistance. Diabetes 57:2737-2744

56. Aitken JF, Loomes KM, Konarkowska B, Cooper GJS (2003) Suppression of the conversion of human amylin into insoluble amyloid by polycyclic compounds. Biochem J 374:779-784

57. Treusch S, Cyr DM, Lindquist S (2009) Amyloid deposits: protection against toxic protein species? Cell Cycle 8:1668-1674 